\title{
SIGNPOST INDEX
}

\section{A}

Abies, variation of monoterpenes in, 398

Alkaloids, chemical races of lupine, 383

Ambrosia, chemical races of sesquiterpenes, in 393

Angiosperms, phenalenones of, 524

phylogeny and evolutionary trends in, 367

time of origin, 546

Anthocyanins and betalains, comparative biosynthesis of, 507

Anthraquinones, comparative biosynthesis of, 487

Antibiotics, effect on tetracycline synthesis, 472

\section{B}

Bacterial ferredoxins with two iron atoms, 569

Betalains and anthocyanins, comparative biosynthesis of, 507

Biosynthetic pathways, in fungi, 435

in higher plants, 487

Bruchids, effect of secondary compounds on feeding, 530

\section{$\mathrm{C}$}

$\mathrm{m}$-Carboxyaromatic amino acids, biosynthesis of, 495

Carotenoids, biosynthesis in fungi, 448

Centrospermae, betalains and anthocyanins of, 507

Chemical characters, nature and handling of plant, 370

variability of plant, 372

Chemical fossils, geochemistry of, 591, 611

Cyanogenic glucosides, in geographical races, 383

Cytochrome c, amino acid seyuence of, 540 evolution of higher plant, 539

\section{D}

Diagenesis, changes in lipids in sediments as models of, 617,623

Douglas fir, monoterpenes in geographical races of, 401,411

\section{E}

Empetrum, flavonoid variation in geographical races of, 392

Environment, aquatic, comparison with fossilisation, 613

Enzymes of flavonoid biosynthesis, 503

\section{$F$}

Ferns, flavonoids in chemical races of, 389

Ferredoxins, amino acid sequence of, 569

evolution of, 553

physical properties of, 558

Flavonoids, importance in geographical races, $386,388,389,392$

comparative biosynthesis of, 498

enzymes concerned in biosynthesis. 503

Flowering plants, time of origin, 546

phylogeny and evolutionary trends in, 367

Fossils, chemical, in relation to organic geochemistry, 591, 611

Fungi, comparative aspects of isoprene pathway in, 435

structure of phenalenones, 521

taxonomic relationships of Mucorales, 437

\section{G}

Geochemistry, organic, trends in, 591,611

Geochemical transformations, rates and mechanisms, 600

comparison with changes in sediments, 617

Geographical races, chemical differences in, $377,401,411$

\section{$\mathrm{H}$}

Hydroxybenzoic acids, comparative biosynthesis of, 490

\section{1}

Isoprene pathway, comparative aspects in fungi, 435

Insects, feeding habits and plant secondary compounds, 532

\section{L}

Lactones, sesquiterpenoid, chemical races of, 393

Leguminosae, alkaloids in chemical races, 384 a mino acids in seeds and insect feeding, 532

Lemnaceae, flavanoids in chemical races of, 388

Lichens, lichen acids of chemical races of, 379

Lignin, comparative biosynthesis of, 497

Lipids, changes in sediments as models of diagenesis, 617,623

Lupine alkaloids, in geographical races, 384 
$\mathrm{M}$

Malonyl-CoA, biosynthetic precursor of, for tetracyclines, 465,469

Monoterpenes. variation in races of Ahic', 398 variation in races of Pseudotsuga (Douglas fir). 401,411

Mucorales, taxonomic relationships of, 437

\section{N}

Nuclentide seyuences, evolution of rRNA, 582

\section{P}

Palaeontology and organic geochemistry. 592

Petroleum. origin of steroid acids in. 633

Phenalenones, biosynthesis of, 515

in angiosperms, 524

in fungi, 521

Phylogenetic trees, construction from protein data, 542

Phytophagous insects, effect of plant secondary compounds on, 530

Plant ferredoxins, amino acid composition, 557

Plant systematics, role of chemistry in. 355

Polymers, formation of in rocks, 601

Porphyrins, significance of fossil, 605

Prenols, occurrence in fungi, 447

Proteins, sequences of amino acids in, 541, 568

Pseudotsuga menziessii. variation of monoterpenes in, 401, 411

Pyruvate, as a source of acetyl and malonyl CoA, 465

\section{Q}

Quebrachitol, comparative biosynthesis of, 491
R

Races, chemistry of geographical, 377. 401 , 411

Ribonucleic acids, base composition of, 581 evolution of nucleotide scyuence in, 582 evolution of ribosomal, 579 instability of $28.5,584$ molecular weights of, 580

Ribosomes, in the biosynthesis of tetracyclines, 477

RNA of, 579

structure of, 581

\section{S}

Secondary compounds, importance in plant community structures, 529

Sescuiterpenoid lactones, variation in geographical races of Ambrosia, 393

Shikimic acid pathway. comparative regulation of. 494

Steroid acids, origin of petroleum, 633

Steroids, biosynthesis in fungi, 439

changes taking place in estuarine sediments, 627

comparative biosynthesis of, 445

contribution by animal, to petroleum, 494

Streptomyces aureofaciens, biosynthesis of tetracyclinc in, 463

\section{$T$}

Taxonomy, nature of, 358

Terpenes. geographical races of volatile, 397. 401,411

Tetracycline, factors effecting the biosynthesis of, 463

Trisporic acid, biosynthesis in fungi. 453

U

Ubiquinones, in fungi, 446 